\title{
PENGARUH SELF EFFICACY TERHADAP HASIL BELAJAR MAHASISWA BERPRESTASI (MAWAPRES) STKIP PGRI BANGKALAN
}

\author{
Atya Rizkiana \\ STKIP PGRI BANGKALAN \\ atyarizkiana@stkippgri-bkl.ac.id
}

\begin{abstract}
The purpose of this research is to know how big influence of self efficacy variable consist of; Level, strength, generality to the learning outcomes of Mawapres (outstanding students) in STKIP PGRI Bangkalan. Where, students are taken are students who follow the mawapres in STKIP PGRI Bangkalan as many as 22 people. The analysis technique used multiple linear regression analysis. The hypothesis of this study is Self Efficacy consisting of variable level, strength and generality influence on student learning outcomes. Based on hypothesis testing is acceptable. The findings of this study indicate that self efficacy variables consisting of: Level, Strength, and Generality have a significant effect on the result of learning mawapres STKIP PGRI Bangkalan. And obtained the value $\left(R^{2}\right)=0.643$ means the variable Level, Strength, and Generality gives the effect of $64.3 \%$ of academic achievement, while the remaining $35.7 \%$ influenced by other factors outside the variables studied.
\end{abstract}

Keywords: SelfEfficacy, Learning Outcomes, Student Achievement

\begin{abstract}
Abstrak
Tujuan dari penelitian ini adalah untuk mengetahui seberapa besar pengaruh variabel self efficacy yang terdiri dari; level, strength, generality terhadap hasil belajar Mawapres (mahasiswa berprestasi) di STKIP PGRI Bangkalan. Dimana, mahasiswa yang diambil adalah mahasiswa yang mengikuti mawapres di STKIP PGRI Bangkalan sebanyak 22 orang. Teknik analisis menggunakan analisis regresi linier berganda. Hipotesis penelitian ini adalah Self Efficacy yang terdiri dari variabel level, strength dan generality berpengaruh terhadap hasil belajar mahasiswa. Berdasarkan pengujian hipotesis dapat diterima. Temuan dari penelitian ini menunjukkan bahwa variable self efficacy yang terdiri dari: Level, Strength, dan Generality berpengaruh signifikan terhadap hasil belajar mawapres STKIP PGRI Bangkalan. Dan diperoleh nilai $\left(\mathrm{R}^{2}\right)=0,643$ berarti variabel Level, Strength, dan Generality memberikan pengaruh sebesar $64,3 \%$ terhadap prestasi akademik, sedangkan sisanya sebesar $35,7 \%$ dipengaruhi oleh faktor lain di luar variabel yang diteliti.
\end{abstract}

Kata Kunci: SelfEfficacy, Hasil Belajar, Mahasiswa Berprestasi 


\section{PENDAHULUAN}

Kenyataannya pendidikan merupakan sebuah proses perubahan sikap dan tingkah laku seseorang dalam mendewasakan diri menuju pribadi yang lebih baik, lebih teratur dan lebih terarah. Pendidikan berlangsung bukan hanya ketika seseorang melakukan aktifitas sekolah saja melainkan pada kehidupan sehari-hari melalui misalkan pada proses pengajaran dan pelatihan.

Kenyataan yang terjadi dalam dunia pendidikan khususnya mahasiswa sekolah tinggi atau perguruan tinggi hasil belajar tidaklah cukup karena banyak mahasiswa yang masih kurang percaya diri, tidak yakin dengan kemampuan yang dimiliki atau pasrah saja menerima nasib. Kondisi yang seperti ini begitu sangat memprihatinkan dan jika dibiarkan tanpa adanya tindakan tentu saja akan berakibat buruk terhadap masa depan mahasiswa itu sendiri. Sebagai tenaga pendidik yang terlibat dalam lembaga pendidikan sudah seharusnya membantu meningkatkan keyakinan mahasiswa. Adapun keyakinan diri (self efficacy) dipandang mampu mengubah tingkah laku seseorang dalam mencapai tujuannya. Self efficacy menjadi salah satu faktor pendukung yang penting dalam kepribadian untuk meningkatkan prestasi akademik maupun non akademik mahasiswa. Keyakinan diri mahasiswa yang disempurnakan dengan motivasi dan kemampuan dalam diri mahasiswa dapat menentukan prestasi akademik maupun non akademik mahasiswa tersebut.

Adapun tolak ukur keberhasilan atau prestasi akademik mahasiswa melalui penilaian yang dilakukan dari hasil belajar yang dicapai mahasiswa dalam proses belajar selama menempuh pendidikan di sekolah tinggi maupun perguruan tinggi. Prestasi akademik tersebut diketahui dari suatu tingkat keberhasilan seseorang yang dilihat dari hasil belajar mahasiswa dalam menguasai tugas belajar dalam periode dan tingkatan tertentu yang meliputi aspek pengetahuan (kognitif), sikap (afektif) dan keterampilan (psikomotorik) serta prediksi keberhasilan mahasiswa dalam dunia non akademik seperti halnya pengembangan minat dan bakatnya.

Kesuksesan hasil belajar mahasiswa tidak hanya ditentukan oleh kemampuan intelektual semata melainkan didukung oleh keyakinan diri dan kemampuan emosional mahasiswa dalam menghadapi segala permasalahan dan kesulitan-kesulitan yang ada. Sekolah tinggi maupun perguruan tinggi sebagai lembaga pendidikan tertinggi seharusnya dapat mencetak dan melahirkan mahasiswa berkualitas sebagai agent of change, agent of control dan agent social yang siap mengabdi kepada masyarakat dan menjadi pelopor sebuah perubahan bangsa yang lebih baik melalui pendidikan yang berkualitas. STKIP PGRI Bangkalan sebagai salah satu sekolah tinggi ilmu keguruan yang ada di pulau Madura khususnya Bangkalan sesungguhnya tidak luput dari dari tuntutan ini.

STKIP PGRI Bangkalan merupakan sekolah tinggi ilmu keguruan atau perguruan tinggi yang sedang berkembang dengan perkembangan yang cukup pesat di setiap tahunnya dengan jumlah mahasiswa, dosen atau tenaga pengajar serta kualitas lulusan terbaik khususnya di Bangkalan. STKIP PGRI Bangkalan merupakan sekolah tinggi yang mencetak guru profesional dan tergabung dalam Persatuan Guru Republik Indonesia. Berdasarkan uraian latar belakang masalah tersebut, maka dapat diambil sebuah judul "Pengaruh Self Efficacy Terhadap Hasil Belajar Akademik Mahasiswa Berprestasi (Mawapres) STKIP PGRI Bangkalan”.

\section{METODE PENELITIAN}

Populasi dari penelitian ini adalah seluruh mahasiswa STKIP PGRI Bangkalan yang terdiri dari keseluruhan prodi yang ada 
di STKIP PGRI Bangkalan. Mahasiswa secara keseluruhan/populasi berjumlah kurang dari 100 orang, maka seluruh mahasiswa tersebut dijadikan obyek penelitian, sehingga penelitian ini dapat disebut dengan penelitian populasi.

\section{Metode Analisa Data}

Teknik analisis data dalam penelitian ini yaitu berupa penelitian kuantitatif dengan menggunakan statistik. Setelah diperoleh data mengenai self efficacy dan hasil belajar, peneliti perlu melakukan analisis statistik deskriptif dan statistik inferensial (statistic induktif). Melalui Uji Validitas dan Uji Reliabilitas. Metode Pengujian Hipotesis dengan Uji F, Uji T, Koefisien Determinasi $\left(\mathrm{R}^{2}\right)$ dan Koefisien Korelasi Berganda ( R).

\section{HASIL DAN PEMBAHASAN}

Berdasarkan hasil pengujian terhadap hipotesis pertama, penelitian ini berhasil menemukan adanya pengaruh positif yang signifikan antara variabel level $\left(\mathrm{X}_{1}\right)$, strength $\left(X_{2}\right)$, generality $\left(X_{3}\right)$ terhadap hasil belajar mahasiswa berprestasi (mawapres) STKIP PGRI Bangkalan. Hal ini dibuktikan dengan nilai signifikansi pada tabel ANOVA tersebut yang menunjukkan Nilai F-hitung $(10,785) \geq$ nilai F-tabel $(3,16)$ dengan nilai signifikansi $0,000 \leq 0,05$ maka Ho ditolak dan $\mathrm{H}_{\mathrm{a}}$ diterima sehingga variabel level $\left(\mathrm{X}_{1}\right)$, strength $\left(\mathrm{X}_{2}\right)$, generality $\left(\mathrm{X}_{3}\right)$ secara simultan (bersamasama) terdapat pengaruh yang signifikan terhadap hasil belajar mahasiswa berprestasi (mawapres) STKIP PGRI Bangkalan.

Di antara variabel self efficacy, yang terdiri dari variabel level $\left(\mathrm{X}_{1}\right)$, strength $\left(\mathrm{X}_{2}\right)$, generality $\left(\mathrm{X}_{3}\right)$, ternyata variabel generality yang mempunyai pengaruh dominan dalam meningkatkan hasil belajar mahasiswa. Penghitungan nilai signifikansi dari hasil penelitian ini menunjukkan bahwa nilai variabel generality $\left(\mathrm{X}_{3}\right)$ sebesar 3,475 yang berarti 3,475 $\geq 1,73$ yang menyatakan bahwa terdapat pengaruh yang signifikan antara variabel generality $\left(\mathrm{X}_{3}\right)$ terhadap hasil belajar mahasiswa berprestasi (mawapres) STKIP PGRI Bangkalan. Sehingga dapat disimpulkan bahwa variabel generality memiliki pengaruh yang dominan terhadap hasil belajar mahasiswa berprestasi dibandingkan dengan variabel level dan variabel strength. Hal ini tidak membuktikan pengujian hipotesis yang kedua, yang sebelumnya menyatakan bahwa diduga variabel strength memiliki pengaruh dominan terhadap hasil belajar mahasiswa berprestasi (mawapres) STKIP PGRI Bangkalan.

Hasil nilai koefisien determinasi dan koefisien korelasi berganda menyatakan bahwa self efficacy yang terdiri dari variabel level $\left(\mathrm{X}_{1}\right)$, strength $\left(\mathrm{X}_{2}\right)$, generality $\left(\mathrm{X}_{3}\right)$ tidak memiliki pengaruh yang signifikan terhadap hasil belajar mahasiswa sebagai variabel terikat. Self efficacy yang terdiri dari variabel level $\left(\mathrm{X}_{1}\right)$, strength $\left(\mathrm{X}_{2}\right)$, generality $\left(\mathrm{X}_{3}\right)$ tidak memiliki kontribusi besar terhadap hasil belajar mahasiswa yang dalam penghitungan data dengan menggunakan program SPSS sebesar $64,3 \%$ dan sisanya yang berjumlah $35,7 \%$ dipengaruhi oleh faktor lain yang tidak masuk dalam penelitian ini.

Self efficacy pada diri mahasiswa berprestasi memiliki pengharapan dalam menyelesaikan kesulitan yang dihadapi, kemantapan atau kekuatan dalam menghadapi permasalahan serta penguasaan materi yang memiliki pengaruh penting dalam pencapaian hasil belajar mahasiswa berprestasi di STKIP PGRI Bangkalan. Seseorang dengan self efficacy rendah merasa bahwa keadaan lebih sulit dari keadaan yang sebenarnya bahkan selalu berpandangan sempit dalam menyelesaikan suatu masalah dan tidak termasuk dalam mahasiswa berprestasi.

Mahasiswa yang lolos seleksi menjadi mahasiswa berprestasi dan mendapat beasiswa PPA tentunya sebagian besar 
mereka memiliki self efficacy yang tinggi untuk terus berkarya dan berprestasi. Hal ini menunjukkan bahwa mahasiswa berprestasi (mawapres) lebih unggul daripada mahasiswa lainnya. Perilaku yang mereka miliki mampu menjadi contoh atau panutan bagi mahasiswa lainnya. Di samping aktif dalam organisasi dan berperilaku baik terhadap dosen dan sesamanya juga bisa meningkatkan hasil belajarnya selama menempuh perkuliahan di STKIP PGRI Bangkalan untuk terus meningkatkan kemampuannya menjadi mahasiswa yang berprestasi dan mampu mengharumkan nama STKIP PGRI Bangkalan dalam dunia pendidikan sebagai calon tenaga pendidik yang professional.

Dalam penelitian ini penguasaan atau keluasan (generality) yang ada pada diri mahasiswa berprestasi di STKIP PGRI Bangkalan mampu meningkatkan keyakinan diri seseorang sehingga berpengaruh terhadap hasil belajar mahasiswa. Sedangkan mampu menghadapi berbagai tingkat kesulitan yang terjadi dan kekuatan dalam menghadapi permasalahan belum memiliki pengaruh yang signifikan terhadap hasil belajar mahasiswa tersebut. Namun self efficacy yang terdiri dari variabel level $\left(\mathrm{X}_{1}\right)$, strength $\left(\mathrm{X}_{2}\right)$, generality $\left(\mathrm{X}_{3}\right)$ memiliki pengaruh yang positif terhadap keyakinan diri seseorang tergantung dari tinggi atau rendahnya self efficacy dari seseorang tersebut yang dapat mempengaruhi hasil belajar mahasiswa.

Memupuk rasa kepercayaan diri pada seseorang sangat penting agar tidak mudah menyerah dalam menghadapi segala tingkat kesulitan yang akan dihadapi mahasiswa, kemudian memiliki kemantapan atau kekuatan keyakinan bahwa mampu menghadapi segala persoalan dan tentunya menguasai materi atau segala bidang untuk meningkatkan hasil belajarnya. Dengan demikian hal tersebut mampu menghasilkan mahasiswa-mahasiswa yang memiliki prestasi yang tinggi guna mencapai visi misi dan tujuan STKIP PGRI Bangkalan.

Oleh karena itu, self efficacy bukan hanya tertanam pada mahasiswa berprestasi saja melainkan harus tertanam dan ditanamkan sejak dini kepada seluruh mahasiswa yang ada di lingkungan STKIP PGRI Bangkalan. Bahkan dipandang perlu menanamkan kepada seluruh civitas akademika STKIP PGRI Bangkalan untuk lebih meningkatkan keyakinan diri. Perlu diingat bahwa self efficacy atau keyakinan diri tidak akan pernah muncul kecuali kita sendiri yang mau memunculkannya sendiri untuk terus menjadi kepribadian baik dalam diri sendiri.

Berilah kesempatan kepada diri kita untuk dapat memunculkan keyakinan diri tersebut. Sesuatu yang kita yakini pasti akan berhasil dan itu semua tergantung dari niat dan keyakinan itu sendiri. Bila niat atau keyakinan diri kita baik maka kita akan mendapatkan hasil yang baik. Tetapi sebaliknya, apabila niat atau keyakinan diri kita buruk maka kita akan mendapatkan hasil yang buruk pula.

\section{PENUTUP}

\section{Simpulan}

Berdasarkan analisis data, pengujian hipotesis dan interpretasi yang telah dilakukan tentang Pengaruh Self Efficacy Terhadap Hasil Belajar Mahasiswa Berprestasi (Mawapres) STKIP PGRI Bangkalan. Maka dapat dikemukakan beberapa hal yang menjadi simpulan dari penelitian ini yaitu :

1. Berdasarkan hasil uji hipotesis terhadap hipotesis I menunjukkan bahwa penelitian ini berhasil menemukan adanya pengaruh positif dan signifikan antara variabel self efficacy yang terdiri dari variabel level $\left(\mathrm{X}_{1}\right)$, strength $\left(\mathrm{X}_{2}\right)$, generality $\left(\mathrm{X}_{3}\right)$ terhadap hasil belajar mahasiswa berprestasi (mawapres) STKIP PGRI Bangkalan tahun 2015. Dari hasil pengujian pada tabel Anova menunjukkan 
Nilai F-hitung $(10,785) \geq$ nilai F-tabel $(3,16)$ dengan nilai signifikansi $0,000 \leq$ 0,05 maka Ho ditolak dan $\mathrm{H}_{\mathrm{a}}$ diterima sehingga variabel level $\left(\mathrm{X}_{1}\right)$, strength $\left(\mathrm{X}_{2}\right)$, generality $\left(\mathrm{X}_{3}\right)$ secara simultan (bersamasama) terdapat pengaruh yang signifikan terhadap hasil belajar mahasiswa berprestasi (mawapres) STKIP PGRI Bangkalan.

2. Berdasarkan hasil uji hipotesis ke II hasil penelitian secara parsial melalui uji $\mathrm{t}$ menunjukkan bahwa variabel level $\left(\mathrm{X}_{1}\right)$ tidak terdapat pengaruh yang signifikan karena nilai t-hitung $(-0,431) \leq$ nilai $t-$ tabel $(3,16)$ dengan nilai signifikansi $0,672 \geq 0,05$. Variabel strength $\left(\mathrm{X}_{2}\right)$ juga tidak terdapat pengaruh yang signifikan karena nilai t-hitung $(-0,402) \leq$ nilai $\mathrm{t}$ tabel $(3,16)$ dengan nilai signifikansi $0,692 \geq 0,05$. Sedangkan pada variabel generality $\left(\mathrm{X}_{3}\right)$ terdapat pengaruh yang signifikan terhadap hasil belajar mahasiswa berprestasi (mawapres) STKIP PGRI Bangkalan dikarenakan nilai thitung $(3,475) \geq$ nilai t-tabel $(3,16)$ dengan nilai signifikansi $0,003 \leq 0,05$.

3. Berdasarkan hasil uji hipotesis terhadap hipotesis III, penelitian ini menunjukkan bahwa variabel self efficacy yang terdiri dari variabel level $\left(\mathrm{X}_{1}\right)$, strength $\left(\mathrm{X}_{2}\right)$, generality $\left(\mathrm{X}_{3}\right)$ yang menunjukkan variabel yang paling dominan yaitu variabel generality $\left(\mathrm{X}_{3}\right)$ terhadap hasil belajar mahasiswa berprestasi (mawapres) STKIP PGRI Bangkalan dengan nilai t-hitung terbesar yaitu 3,475 dengan nilai signifikansi $0,003 \leq 0,05$.

\section{Saran}

Beberapa saran yang dapat disampaikan oleh peneliti diantaranya:

1. Penelitian yang dilakukan hendaknya tidak hanya pada mahasiswa berprestasi tetapi kepada seluruh mahasiswa.
2. Pada saat pengambilan data hendaknya tidak hanya menggunakan instrumen berupa skala saja pada mahasiswa, tetapi juga wawancara dengan dosen sehingga data yang dihasilkan sesuai dengan hasil wawancara dari dosen.

3. Penelitian selanjutnya, diharapkan agar hasil penelitian ini dapat dipakai sebagai pedoman untuk mengembangkan penelitian selanjutnya dengan pokok bahasan yang lebih luas.

\section{DAFTAR PUSTAKA}

Arikunto S. 2006. Prosedur Penelitian Suatu Pendekatan Praktik. Jakarta: Rineka Cipta.

Bahri, Syaiful. 2011. Psikologi Belajar. Jakarta:PT. Rineka Cipta.

Ernawati. 2013. Pengaruh Efikasi Diri, Konsep Diri, Aktivitas Belajar dan Kemandirian Belajar Terhadap Hasil Belajar Matematika Pada Siswa Kelas VII SMP Negeri Se-Kecamatan Somba Opu. Tesis. Tidak diterbitkan. Makassar: Universitas Negeri Malang (UNM).

Fitriana, Ihsan, Annas. 2015. Pengaruh Efikasi Diri, Aktivitas, Kemandirian Belajar dan Kemampuan Berpikir Logis Terhadap Hasil Belajar Matematika Pada Siswa Kelas VIII SMP. Journal of EST. Vol. 1.

Ghufron, M. N. \& Risnawita, R. 2010. Teoriteori Psikologi. Jogyakarta: Ar-Ruzz Media Group.

Hamalik, Oemar. 2012. Proses Belajar Mengajar. Jakarta: Sinar Grafika.

Hermino, Agustinus. 2014. Kepemimpinan Pendidikan di Era Globalisasi. Yogyakarta: Pustaka Pelajar. 
Narbuko, Cholid dan Abu Achmadi. 2013. Metodologi Penelitian. Jakarta: Bumi Aksara.

Nirwana Gita Pertiwi. 2015. Pengaruh Self Efficacy Terhadap Hasil Belajar Pada Siswa Kelas V Sekolah Dasar Daerah Binaan IV Kecamatan Cilacap Selatan Kabupaten Cilacap. Universitas Negeri Semarang.

Ormrod, J. E. 2009. Psikologi Pendidikan Membantu Siswa Tumbuh dan Berkembang. Edisi Keenam. Jakarta. Erlangga.

Purwanto. 2014. Evaluasi Hasil Belajar. Yogyakarta: Pustaka Pelajar.

Pramesti, Getut. 2013. Smart Olah Data Penelitian Dengan SPSS 21. Jakarta : PT. Elex Media Komputindo.
Prawira, Purwa Atmaja. 2014. Psikologi Pendidikan dalam Perspektif Baru. Yogyakarta:AR RUZZ Media.

Slameto. 2010. Belajar dan Faktor-Faktor yang Mempengaruhinya. Jakarta: Rineka Cipta.

Sugiyono. 2010. Metode Penelitian Pendidikan:Pendekatan Kuantitatif, Kualitatif, dan $R \& D$. Bandung: Alfabeta.

Sugiyono. 2011. Metode Penelitian Kuantitatif, Kualitatif, dan Kombinasi (Mixed Methods). Bandung: Alfabeta.

Sugiyono. 2013. Metode Penelitian Pendidikan (Pendekatan Kuantitatif, Kualitatif dan R\&D). Bandung: Alfabeta. 